ARTIGO

\title{
A crise do multilateralismo econômico e o Brasil
}

LUIZ A. P. SOUTO MAIOR*

Rev. Bras. Polít. Int. 47 (2): 163-190 [2004]

\section{Introdução}

$\mathrm{O}$ correto funcionamento e a estabilidade de qualquer sistema internacional dependem do efetivo apoio que ele receba dos países que o integram - especialmente daqueles de maior peso específico - e de que a distribuição dos benefícios dele derivados seja geralmente percebida como razoavelmente eqüitativa. No caso do sistema econômico multilateral estabelecido ao fim da Segunda Guerra Mundial, as duas condiçōes, embora de maneiras diferentes, foram - gradual, mas rapidamente deixando de ser preenchidas de forma satisfatória.

Por um lado, a liderança dos países economicamente mais avançados, particularmente dos Estados Unidos, em favor da efetiva liberalização do comércio internacional foi crescentemente qualificada, em função das mudanças na sua competitividade relativa. Por outro, ganhou força entre os países em desenvolvimento a noção de que, dada a sua menor competitividade global, um sistema formalmente igualitário levava a um desvio distributivo em favor das economias mais avançadas. Em princípios da década de 1960, a pressão por uma reforma do sistema levou à convocação da I Conferência das Nações Unidas para o Comércio

\footnotetext{
* Embaixador aposentado.
} 
e o Desenvolvimento (mais conhecida por sua sigla inglesa Unctad). Em termos concretos, os resultados diretos da conferência foram modestos, mas a iniciativa marcou uma visão mais clara da divergência de interesses entre países desenvolvidos e em desenvolvimento.

Em 1983, Fred Bergsten já assinalava que o enorme progresso feito no sentido da liberalização do comércio internacional vinha claudicando desde meados da década de 1970. Observava ele que, apesar dos importantes compromissos assumidos na Rodada Tóquio de negociações comerciais, no Gatt, medidas protecionistas novas ou mais severas tinham surgido em setores importantes como os de têxteis e confecções, aço e automóveis, além da continuada proteção e dos subsídios à agricultura. Por sua vez, William Cline afirmava que "o sistema internacional de comércio está sob grande pressão e parece provável que permaneça sob grande - ou maior - pressão no futuro previsível". ${ }^{1}$ A previsão tem-se realizado. Em 1991, Jagdish Bhagwati, de forma mais incisiva, constatava estar o sistema mundial de comércio "em perigo", ameaçado pelos defensores do "comércio administrado, do unilateralismo agressivo e do regionalismo." 2 Em um trabalho mais recente e de enfoque mais amplo, Robert Gilpin conclui que

o regionalismo econômico, a instabilidade financeira e o protecionismo comercial ameaçam seriamente a estabilidade e a integração da economia global, cujo futuro dependerá das políticas externas, das políticas econômicas internas e das relações políticas das grandes potências econômicas. Se os Estados Unidos não reassumirem seu papel de liderança, é provável que a Segunda Grande Era do capitalismo venha a desaparecer, como a primeira. ${ }^{3}$

O presente artigo é uma breve reflexão sobre como se chegou a tal estado de coisas e sobre alguns dos desafios internacionais que ele nos coloca.

\footnotetext{
${ }^{1}$ CLINE, William R. (ed), Trade Policy in the 1980's. Washington: Institute for International Economics 1983, 1 p.

2 BHAGWATI, Jagdish, The World Trading System at Risk. New Jersey: Princeton University Press, 1991.

${ }^{3}$ GILPIN, Robert, $O$ desafio do Capitalismo Global-a economia mundial no século XXI. Rio de Janeiro: Editora Record, 2004, 472 p.
} 


\section{O multilateralismo tutelado}

Ao término da Segunda Guerra Mundial, a comunidade internacional, sob a liderança dos Estados Unidos, pôs-se de acordo sobre o estabelecimento de uma estrutura jurídico-institucional de âmbito mundial, com o objetivo de disciplinar as relaçóes econômicas entre os Estados. Em tese, tratava-se de assegurar que as inevitáveis rivalidades internacionais não tomassem rumos nocivos ao bem comum. Mais concretamente, visava-se a coibir práticas que, sobretudo no período entre os dois grandes conflitos bélicos do século passado, haviam contribuído para agravar os problemas econômicos e políticos internacionais, culminando na Grande Depressão e na guerra de 1939-1945. Na prática, chegou-se, como seria de esperar em uma negociação de tal envergadura entre parceiros extremamente desiguais, a um conjunto de normas que, embora formalmente igualitárias, deveriam, particularmente nas circunstâncias do mundo de então: favorecer a potência hegemônica e seus principais aliados.

$\mathrm{Na}$ área comercial, chegou-se ao Acordo Geral de Tarifas e Comércio (mais conhecido pela sua sigla inglesa, Gatt), pela qual se deveria promover a crescente liberalização do comércio internacional. Para tanto, seus integrantes comprometiam-se com a pronta eliminação das barreiras não-tarifárias, a gradual redução de tarifas aduaneiras por meio de concessóes recíprocas em sucessivas rodadas de negociações e a extensão de tais reduções a todas as partes contratantes, pela aplicação da cláusula de nação mais favorecida. Dava-se, assim, um primeiro e importante passo no caminho da redução dos obstáculos ao comércio internacional e criava-se um quadro normativo-institucional tendente a manter a dinâmica do processo liberalizador. Num primeiro momento, o grande beneficiário do novo estado de coisas foi a economia americana, com uma capacidade competitiva ímpar na época. Em uma segunda etapa, à medida que avançava o processo de reconstrução, dele passariam a beneficiar-se também as demais potências industriais, vencedoras e vencidas, cujas economias tinham sido arruinadas pela guerra. Buscavase, dessa maneira, coibir a tendência a exportar as próprias dificuldades econômicas por meio de medidas protecionistas, como ocorrera com vários países no entreguerras. 
O processo de liberalização econômica multilateralmente administrado não seria, porém, eficaz se não cobrisse, também, a conduta internacional dos Estados na área financeira. Criou-se, portanto, o Fundo Monetário Internacional (FMI) e, complementarmente, o Banco Internacional de Reconstrução e Desenvolvimento (Bird). Com o primeiro, estabeleceu-se um sistema de paridades fixas entre as diferentes moedas, de modo a evitar o recurso das desvalorizações competitivas antes praticadas. Ao mesmo tempo, para evitar que países com dificuldades conjunturais de balanço de pagamentos sucumbissem à tentação das velhas práticas, o FMI se prontificava a prestar-lhes ajuda, desde que respeitassem as disciplinas do sistema. Eram as famosas condicionalidades do Fundo. Assim, para um país a braços com dificuldades conjunturais em suas contas externas, tornava-se menos penoso aceitar a disciplina do sistema do que arcar com os ônus econômicos e políticos de romper com ele, recorrendo a medidas protecionistas. Já as dificuldades de caráter estrutural, fossem de reconstrução ou de desenvolvimento, deveriam, em tese, ser atendidas pelo Bird.

De maneira muito simplificada, este foi o esquema geral ao qual, segundo se acordou, deveria ficar submetida a economia mundial. Sua grande vantagem era que o comportamento dos Estados nacionais, antes casuísta e arbitrário, deveria, a partir de então, pautar-se por regras fixadas pela comunidade internacional e aplicadas por organismos multilaterais, segundo procedimentos aceitos por todos. Tal fato representou, por si só, um considerável avanço, ainda que, em vários pontos, a excelência das regras substantivas então acordadas pudesse ser discutida. Como esquema normativo de âmbito mundial, o novo sistema padecia, entretanto, de uma falha essencial. Negociado, em última análise, entre os Estados Unidos e seus grandes aliados, ele era particularmente adequado para regular as relaçóes entre as grandes economias capitalistas - inclusive as potências vencidas, que por motivos políticos Washington, desejara cooptar - e destas com as menos avançadas. Adaptava-se mal, porém, às economias centralmente planificadas e à defesa de objetivos econômicos fundamentais dos países em desenvolvimento. Era, em última análise, um sistema multilateral tutelado pelas grandes economias capitalistas, especialmente os Estados Unidos, de cuja liderança dependia o seu funcionamento. 


\section{A gradual deformação do sistema}

Em meados da década de 1940, as condições internacionais eram particularmente favoráveis à implantação e ao funcionamento de uma estrutura normativo-institucional com as características acima resumidas. Entre os países industrializados do Ocidente, os Estados Unidos - então campeão do liberalismo econômico - gozavam de condições singulares de liderança. Por um lado, sua economia respondia por mais de um terço do produto mundial, sua assistência material e política era indispensável à reconstrução dos países arruinados pela guerra, tanto vencidos como vencedores, e o dólar tornara-se a moeda-chave do sistema financeiro acordado em Bretton Woods, que estabelecia, efetivamente, um padrão ouro-dólar. Assim, a hegemonia econômica americana era, nas circunstâncias da época, incontestável. A superioridade na área econômica era ainda reforçada pela conjuntura política e militar, que fazia dos EUA o protetor indispensável dos países de economia de mercado contra a ameaça representada pelo poderio soviético. Por outro, os países em desenvolvimento, em sua maioria, ainda não tinham conquistado a própria independência. Recorde-se, a título exemplificativo, que a Índia só se tornou independente em 1947. Além disso, mesmo aqueles que já haviam alcançado a situação de Estados soberanos, como os latinoamericanos, tinham escasso poder de negociação e uma noção nem sempre muito clara da incidência das relaçôes internacionais sobre o processo de desenvolvimento econômico. Tudo isso dava a Washington condições excepcionais de ascendência sobre todos os países, desenvolvidos ou em desenvolvimento, do mundo capitalista. Conseqüentemente, dava-lhe também o poder não só de estabelecer um sistema liberal e multilateral de comércio internacional, mas também de fazê-lo prosperar ou definhar, uma vez estabelecido.

Ao longo da segunda metade do século XX, as circunstâncias que tinham levado Washington a promover a implantação do sistema econômico internacional acima resumido foram-se, porém, modificando. Em particular, uma relativa difusão do poder econômico entre um número maior de países e, já no final da década de 1980, o afrouxamento da liderança americana entre os seus próprios aliados, como decorrência do fim da Guerra Fria, teriam ampla repercussão sobre o conjunto da vida internacional. 
Ainda em fins da década de 1940, a reconstrução econômica daqueles países cujas economias tinham sido devastadas pela guerra, mas que, vencedores ou vencidos no grande conflito bélico, tinhamse tornado aliados importantes na Guerra Fria, passou a ser elemento fundamental do esforço, liderado pelos Estados Unidos, de contenção da União Soviética. O êxito do trabalho conjunto de recuperação de economias arrasadas pelo conflito foi um dos pontos altos da política externa americana no pós-Guerra, mas transformou aliados políticos em poderosos competidores econômicos. O Japão sobretudo, pela sua enorme competitividade internacional em áreas de atividade consideradas sensíveis, passou a ser visto como uma ameaça a certos setores produtivos dos Estados Unidos e, logo também, da Europa Ocidental. Ao mesmo tempo, uns quantos países em desenvolvimento - sobretudo asiáticos e, em menor grau, alguns latino-americanos, entre os quais o Brasil desenvolveram uma forte capacidade competitiva setorial em relação às economias industrializadas tradicionais. Tornou-se, assim, difícil às velhas potências industriais manterem-se fiéis ao liberalismo econômico que, sob a liderança dos EUA, tinham defendido e estabelecido como norma internacional. Por outro lado, apesar dos percalços competitivos que afetavam alguns setores de suas indústrias, ainda interessava aos vanguardeiros da economia mundial manter as grandes linhas do sistema estabelecido em meados da década de 1940, desde que a ele só qualificadamente tivessem de obedecer.

O dilema com que se defrontavam era, pois, o de manter um conjunto de normas que assegurasse um regime geralmente liberal de comércio internacional, que tendia a favorecer as economias mais avançadas, porém, ao mesmo tempo, encontrar meios de proteger setores mais vulneráveis do seu aparelho produtivo. Em outras palavras, tratava-se de induzir países mais fracos, porém incomodamente competitivos em algumas áreas, a aceitarem uma espécie de liberalismo econômico à la carte, que promovesse uma liberalização do comércio internacional que favorecia os grandes, mas que, ao mesmo tempo, não impedisse estes últimos de defender setores das suas economias considerados vulneráveis à competição dos pequenos. Tal situação levou, já num primeiro estágio, a praticamente eximir o comércio de produtos agrícolas das normas disciplinadoras do Gatt. Passou-se em seguida a conseguir a aceitação 
multilateral para uma série de práticas espúrias, tendentes a proteger os setores menos competitivos das economias industrializadas tradicionais, sem rejeitar, entretanto, pelo menos formalmente, as linhas básicas do sistema econômico internacional vigente. Assim, por exemplo, países economicamente fortes passaram a negociar bilateralmente com outros mais débeis, porém setorialmente competitivos, restrições "voluntárias" às suas exportações de determinados bens. Por elas, o exportador mais competitivo comprometia-se a limitar, a um certo nível, suas exportações de determinados produtos para o outro. Formalmente, não se tratava de uma barreira à importação, já que era o país exportador que "voluntariamente" se comprometia a manter dentro de um certo limite, mutuamente acordado, suas vendas de determinado produto. $\mathrm{Na}$ prática, o país importador transferia dessa maneira ao exportador boa parte dos ônus de suas próprias restrições à importação. Dentro do mesmo espírito, criaram-se regimes especiais para o intercâmbio internacional de determinadas categorias de bens, como os têxteis, que passou a ser regido inicialmente pelo Acordo sobre Têxteis de Algodão e, posteriormente, pelo Arranjo Multifibras. Buscava-se, assim, legitimar o contingenciamento das exportações naqueles setores em que a dinâmica das vantagens comparativas criara, sobretudo entre os países em desenvolvimento, alguns novos competidores particularmente incômodos para as potências industriais tradicionais.

Paralelamente, os países pobres iam, entretanto, tomando consciência de quanto, sob a capa da igualdade de oportunidades e da defesa da eqüidade, o sistema estabelecido, mesmo sem as práticas espúrias posteriormente adotadas, podia congelar as vantagens comparativas e, conseqüentemente, contribuir para a perpetuação do hiato entre países desenvolvidos e em desenvolvimento. Passaram, pois, a questionar as próprias bases de um sistema que, entretanto, não tinham a força econômica e política necessária para modificar.

Dados o peso econômico crescente dos países em desenvolvimento em seu conjunto e, sobretudo, o clima político da Guerra Fria, que aconselhava não alienar a simpatia do então chamado Terceiro Mundo, os países mais ricos foram, entretanto, levados a, pragmaticamente, fazer algumas concessões às aspirações das nações mais pobres, ainda que da forma menos onerosa possível. Chegou-se assim à criação do Sistema 
Geral de Preferências e, de forma mais abrangente, à aceitação formal da idéia de se conceder um tratamento "especial e mais favorável" aos países em desenvolvimento nas negociaçôes comerciais. Não cabe fazer aqui o exame de cada uma dessas medidas e de seus benefícios efetivos, mas o fato é que, apesar delas, o funcionamento geral do sistema não tem evitado um claro desvio distributivo em favor das economias mais avançadas. Como assinala The Economist, ainda hoje "as tarifas aplicadas pelos países ricos às categorias de bens que as naçōes pobres produzem são, em média, quatro ou cinco vezes mais altas do que as incidentes sobre bens usualmente importados de outros países ricos". ${ }^{4}$

$\mathrm{O}$ que se viu, portanto, desde as primeiras décadas de vigência do sistema de comércio internacional consubstanciado no Gatt, foi a aplicação de normas que, na prática, iam-se afastando crescentemente do ideal declarado de um comércio internacional igualmente livre para todos.

Paralelamente a esses desenvolvimentos na área comercial, o sistema financeiro estabelecido em Bretton Woods ia também sendo erodido. Da forma como então acordado, aquele sistema estabelecia um padrão ouro-dólar, baseado na livre conversibilidade da moeda americana em ouro e na paridade fixa entre as moedas dos países que o integravam. É verdade que se tinha defendido inicialmente a idéia de que só aquele metal deveria funcionar como unidade de reserva internacional. Tal sugestão esbarrava, porém, na evidente escassez de ouro para viabilizar o funcionamento de uma economia e de um comércio mundial que pretendia crescerem rapidamente. Chegou-se, assim, ao entendimento de que moedas nacionais também poderiam ser instrumentos de reserva, desde que livremente conversíveis em ouro a uma taxa determinada. $\mathrm{Na}$ prática, só o dólar americano podia, na época, satisfazer tal condição. Estabeleceu-se assim, efetivamente, um padrão ouro-dólar. Tratava-se, porém, de um esquema dificilmente sustentável a mais longo prazo.

Com as pesadas responsabilidades econômicas e militares assumidas por Washington como líder do bloco ocidental e as necessidades de meios de pagamento de uma economia mundial em expansão, os Estados Unidos passaram a acumular crescentes déficits em contas correntes. Para

${ }^{4}$ The Economist. 6 de setembro de 2003, 61 p. 
corrigir tal desequilíbrio externo, as autoridades monetárias americanas teriam de tomar medidas que não apenas seriam incompatíveis com a manutenção de sua liderança político-militar, mas levariam a economia mundial à recessão. Havia, pois, no Ocidente, um interesse comum na preservação do statu quo. Para os Estados Unidos, ele permitia manter a sua hegemonia; para seus aliados ocidentais, tornava-se possível repousar sobre o poderio bélico americano para garantir a própria segurança, dedicando a objetivos econômicos os recursos que, de outra forma, teriam de ser utilizados para fins militares. Em última análise, era menos oneroso financiar os déficits americanos do que criar e manter um dispositivo bélico próprio que fosse consistente com as necessidades da Guerra Fria. Criara-se, assim, um paradoxo. A expansão econômica do Ocidente passou a depender de um continuado desequilíbrio nas contas externas da potência líder do bloco, o que implicava o debilitamento crescente da moeda-chave do sistema. Chegou-se, finalmente, ao inevitável quando, em agosto de 1971, Washington suspendeu a garantia de conversibilidade do dólar em ouro.

$\mathrm{O}$ que se seguiu foram os passos necessários à retirada, com o mínimo de turbulência, da pedra angular do sistema financeiro criado em Bretton Woods. Num primeiro momento, as consultas internacionais subseqüentes à decisão de Washington levaram ao acordo do Smithsonian, com a desvalorização da moeda americana. A magnitude do problema exigia, porém, mudanças mais amplas. Os entendimentos que se seguiram conduziriam, dois anos mais tarde, ao abandono formal do sistema de paridades fixas.

Assim, no espaço de, aproximadamente, um quarto de século, vários fatores conduziram a consideráveis transformações - ou deformações no sistema econômico internacional estabelecido em fins da Segunda Guerra Mundial. A reconstrução das economias devastadas pelo conflito levou a uma relativa diluição do poder econômico, antes avassaladoramente concentrado nos Estados Unidos. Tal evolução não chegava, entretanto, a comprometer a capacidade de liderança dos Estados Unidos, em razão não só do peso da sua economia, ainda de longe a maior do planeta, mas, sobretudo, da sua posição de baluarte da segurança político-militar do Ocidente. Paralelamente, o Japão e, em menor grau, alguns países em desenvolvimento mais avançados tornaram-se, do ponto de vista 
dos Estados Unidos e dos países da Europa Ocidental, perigosamente competitivos em alguns setores, pondo em risco indústrias consideradas sensíveis nas duas regiōes. No começo da década de 1980, tornara-se patente, como assinalou William Cline, a pressão sobre um sistema internacional de comércio que já não satisfazia inteiramente as aspirações de nenhuma categoria de países. Em última análise, os países ricos mostravam sua pouca disposição de respeitar as normas que eles mesmos tinham estabelecido, enquanto os pobres insistiam em que, antes de serem alteradas, elas fossem cumpridas naquilo que interessava às economias menos avançadas. Em certo sentido, tinha havido uma inversão de posições, com as grandes potências econômicas procurando modificar um sistema que percebiam como insuficientemente favorável aos seus interesses, enquanto os países em desenvolvimento insistiam em obter, primeiro, o cumprimento de promessas feitas e fraudadas.

Nada disso significa que não se tivessem feito enormes progressos no caminho da expansão e da liberalização do comércio mundial, como ilustrado pelo número de países e pelo valor do intercâmbio envolvido nas várias rodadas de negociaçóes comerciais no Gatt. Da primeira, em Genebra, 1947, participaram 23 países e o valor do comércio envolvido foi de 10 bilhões de dólares; em 1973, na rodada Tóquio, houve 99 participantes e o valor do comércio coberto pelas negociações atingiu 155 bilhões de dólares. ${ }^{5}$ A divergência, ainda não resolvida, é em torno da distribuição dos benefícios passados e da fixação de uma agenda e de normas capazes de assegurar resultados mais eqüitativos para o futuro.

\section{Ponto de inflexão?}

Foi contra esse pano de fundo que, na década de 1980, ocorreram dois desenvolvimentos cujas implicações para o futuro do sistema econômico multilateral ainda não estão totalmente claras - a difusão do regionalismo econômico em uma escala até então desconhecida e a inclusão dos chamados "novos temas" na agenda do comércio internacional.

Em tese, existe um conflito entre o enfoque adotado pelo Gatt com vistas à liberalização do comércio internacional e a formação de blocos

${ }^{5}$ Citado em Bhagwati, Jagdish, op. cit., p. 8. 
ou arranjos regionais de comércio. $\mathrm{O}$ primeiro prevê a negociação de reduçōes simultâneas de barreiras tarifárias e a sua extensão "imediata e incondicional” a todas as partes contratantes. O objetivo geral é, pois, universal e não discriminatório, enquanto os arranjos regionais - zonas de livre comércio, uniōes aduaneiras ou mercados comuns - são, por definição, geograficamente seletivos e não têm como objetivo precípuo a liberalização do comércio mundial, mas sim a do intercâmbio entre os países que os integram. Daí, embora permitidos pelo Gatt, serem tratados como uma exceção à cláusula de nação mais favorecida, tal como estabelecida no artigo I do Acordo Geral. É verdade que o estabelecimento de um bloco regional de comércio tem dois efeitos antagônicos: a criação de comércio - sobretudo entre os países que o integram - e o desvio de comércio - principalmente de fora para dentro do bloco. Assim, o impacto de um esquema de integração econômica regional sobre o volume do comércio mundial vai depender do incremento de intercâmbio, positivo ou negativo, que, em cada caso, resulte da interação daqueles dois efeitos antagônicos. Em sentido semelhante, tem-se argumentado que o regionalismo econômico poderá ser uma contribuição, e não um óbice à liberalização do comércio internacional em bases multilaterais, na medida em que os blocos econômicos adotem uma política comercial de cunho liberal e se mantenham abertos ao ingresso de novos membros.

Nas décadas de 1950 e 1960, foram criados vários blocos regionais de comércio, na maioria entre países em desenvolvimento, que tiveram, de modo geral, escasso impacto sobre a estrutura do comércio mundial. A grande exceção foi a assinatura do Tratado de Roma, em 1957, que estabeleceu a Comunidade Econômica Européia (CEE), a qual levaria, quase quatro décadas mais tarde, à constituição da União Européia (UE).

No conjunto, porém, apesar dos entorces já assinalados, o sistema internacional de comércio vigente manteve, até a década de 1970, o formato geral estabelecido ao término da Segunda Guerra Mundial: um esquema multilateral destinado a liberalizar e ampliar o comércio mundial de bens. Isto se deveu principalmente à posição dos Estados Unidos, que, durante cerca de quatro décadas, preferiram burlar os objetivos declarados do sistema recorrendo a formas seletivas de protecionismo, às vezes por meio do exercício de um "unilateralismo agressivo", a aderirem abertamente ao regionalismo discriminatório. 
Tal situação se modificaria a partir de meados dos anos 80, quando Washington assumiu, formalmente, a percepção de que as normas vigentes não vinham servindo adequadamente os seus interesses.

Conseqüentemente, os Estados Unidos, que tradicionalmente tinham sido o grande defensor de um sistema multilateral de comércio mundial, passaram a buscar as vantagens econômicas e políticas do regionalismo econômico. Assim, em 1985, assinaram um acordo de livre comércio com Israel. $\mathrm{O}$ impacto comercial foi quantitativamente pequeno, mas o Estado judeu conseguiu dar um caráter mais permanente ao acesso privilegiado de que já gozava por meio do sistema generalizado de preferências americano, enquanto os Estados Unidos passaram a competir em igualdade de condiçóes com os integrantes da CEE, que já tinham acesso preferencial ao mercado israelense, com base num acordo de 1975 . No ano seguinte - por iniciativa dos canadenses, receosos de que Washington, sujeito a fortes pressões internas em momento de crescente déficit comercial, adotasse medidas protecionistas - iniciaramse negociaçôes com vistas à criação de uma Área de Livre Comércio Estados Unidos-Canadá. O acordo respectivo foi assinado em outubro de 1987. Pouco menos de três anos mais tarde, em março de 1990, foi a vez de o México propor ao seu principal parceiro comercial a conclusão de um acordo de livre comércio. Como o Canadá, os mexicanos aparentemente se preocupavam com a possível imposição de barreiras às suas exportações para os EUA. A essa motivação negativa - de evitar um possível dano - somavam-se consideraçóes positivas, como o desejo de atrair investimentos estrangeiros e de reforçar o apoio às reformas econômicas do governo Salinas, que incluíam a adesão do México ao Gatt e a liberalização unilateral do seu comércio exterior. No ano seguinte, decidiu-se incluir o Canadá nas negociações, com vistas à constituição de uma área de livre comércio que abrangesse toda a América do Norte. O acordo final - com a inclusão dos instrumentos complementares relativos ao meio ambiente e às condições de trabalho, para cobrir as preocupações de Washington com um alegado "dumping social” - só foi aprovado pelo Congresso americano já no governo Clinton.

A Área de Livre Comércio da América do Norte (mais conhecida pela sigla inglesa $\mathrm{Nafta}$ ), até agora, o exemplo mais marcante da conversão de Washington ao regionalismo econômico, reflete também as novas preocupaçôes dos países desenvolvidos em matéria de comércio 
internacional, indo muito além do intercâmbio de mercadorias. O acordo respectivo inclui, além das, já mencionadas, disposiçôes sobre normas trabalhistas e proteção do meio ambiente, outras relativas a serviços e investimentos. Por outro lado, estabeleceu regras de origem particularmente rígidas para determinados setores, como têxteis, automóveis e computadores, de modo a evitar que a proteção então em vigor nessas áreas, pudesse ser contornada por produtores de fora da área.

A idéia de um regionalismo americano capitaneado por Washington não se limitaria, entretanto, à parte setentrional do continente. Em 1990, o presidente Bush (pai) lançou a Iniciativa para as Américas, cujo ponto mais importante foi a proposta de uma vasta área hemisférica de livre comércio, "do Alasca à Terra do Fogo". A idéia teve seguimento no governo do presidente Clinton, que promoveu, em dezembro de 1994, em Miami, a realização de uma Cúpula das Américas, na qual os chefes de Governo dos países do continente (exceto Cuba) se comprometeram com a negociação de uma Área de Livre Comércio das Américas.

Ao mesmo tempo, na América Latina, proliferavam propostas e esquemas formais de integração econômica ou iniciativas tendentes ao aprofundamento de blocos já existentes. Não cabe fazer aqui uma lista exaustiva de tais iniciativas. Alguns exemplos bastam para ilustrar a onda integracionista que parece ter-se apossado da região. Em abril de 1992, os integrantes da Comunidade Econômica do Caribe anunciaram sua intenção de estabelecer um mercado comum; em novembro do ano seguinte, os membros do Mercado Comum Centro-Americano firmaram um acordo para a remoção das barreiras que ainda obstaculizavam o comércio intrazonal; em março de 1994, México e Costa Rica também firmaram um instrumento visando à liberalização do seu comércio bilateral; no mesmo mês, o Brasil propôs a criação de uma Área de Livre Comércio Sul-Americana (Alcsa); três meses depois, Colômbia, México e Venezuela concluíram o acordo do chamado Grupo dos Três, com vistas à criação de uma área de livre comércio entre eles. Mais importante para nós e para o comércio intracontinental, foi firmado, em março de 1991, o Acordo de Assunção, que criou o Mercosul. Para o objeto desta reflexão, pouco importa que os objetivos dessas várias iniciativas possam ter sido distintos ou mesmo antagônicos. A proposta de estabelecimento da Alcsa, por exemplo, responderia à preocupação brasileira com as possíveis conseqüências econômicas e políticas da integração hemisférica 
proposta por Washington, enquanto o Grupo dos Três refletiria o desejo da Colômbia e da Venezuela de acesso à Nafta. No contexto da presente análise, o importante é que todos viram no regionalismo econômico - e não no multilateralismo universalista - a melhor forma de alcançar seus respectivos fins econômicos e políticos.

Enquanto isso, na Europa, o processo de integração, que naquele continente já avançara consideravelmente, foi aprofundado com a assinatura, em julho de 1987, do Ato Europeu Único, cujo objetivo era o estabelecimento, entre os membros da Comunidade Européia (CE), a partir do fim de 1992, de um mercado comum, com plena liberdade de movimento para bens, serviços, pessoas e capital. A esse novo passo, no sentido do aprofundamento da integração, seguiu-se uma nova expansão geográfica do processo, que passaria, a partir de 1991, a incluir no Espaço Econômico Europeu os países da Área Européia de Livre Comércio (Aelc), com exceção da Suíça. Este impulso dado ao regionalismo europeu culminaria com a assinatura do Tratado de Maastricht, em fins de 1991, que criou a União Européia. E o processo continua em andamento, com a conclusão de um tratado constitucional (cuja entrada em vigor ainda depende de sua aprovação final, inclusive por referendo popular, pelos Estados-membro) e as novas e projetadas adesões, que ampliarão ainda mais a União Européia para o Leste e o Sul. A importância deste enorme bloco comercial, que por si só já responde por cerca de $40 \%$ do intercâmbio mundial de bens, é ainda reforçada pela sua rede de tratados de comércio com os signatários das Convenções de Lomé (cerca de setenta ao todo) e mais de uma dezena de países mediterrâneos.

E a tendência geral no sentido da formação de blocos econômicos mais ou menos coesos estende-se também à Ásia. Além do aprofundamento do processo de integração entre Austrália e Nova Zelândia, os seis integrantes da Asean (Brunei, Cingapura, Filipinas, Indonésia, Malásia e Tailândia) lançaram, em janeiro de 1993, um programa de integração com vistas ao estabelecimento, num prazo de 15 anos, de uma área de livre comércio entre eles. Em agosto de 1994, o relatório de um Grupo de Pessoas Eminentes criado pela $\mathrm{Apec}^{6}$ recomendou que os países que

\footnotetext{
${ }^{6}$ Cabe assinalar que a Apec (Ásia Pacific Economic Cooperation) tinha sido criada em 1989, por iniciativa dos Estados Unidos e da Austrália, como um foro de cooperação econômica intra-regional, não se prevendo inicialmente um processo de liberalização comercial entre os participantes.
} 
integravam aquele esquema de cooperação iniciassem um processo de integração econômica com o objetivo de chegar a uma área de livre comércio até 2020. A proposta foi aprovada, em novembro do mesmo ano, por uma reunião de cúpula da Apec, apesar das objeções e reservas da Malásia, e um programa de ação foi definido, um ano depois, numa reunião ministerial realizada em Osaka.

Em suma, as duas últimas décadas do século passado viram o surgimento de um número considerável de blocos econômicos e o aprofundamento de outros já existentes. Seria prematuro afirmar que tal desenvolvimento já se esteja traduzindo numa regionalização do comércio mundial, no sentido de o intercâmbio dentro das várias regiōes estar-se tornando relativamente mais importante do que o praticado multilateralmente, fora de esquemas preferenciais. Seria também precipitado dizer que os blocos regionais já constituem uma ameaça direta ao sistema multilateral. Muito vai depender das políticas mais ou menos protecionistas que tais blocos adotem em relação ao comércio com países de fora da área e no tocante à aceitação de novos membros. O certo, porém, é que um grande número de países, talvez a maioria, passou a considerar que seus interesses econômicos, políticos ou ambos aconselhavam o estabelecimento de vínculos preferenciais com alguns outros. Os agrupamentos daí decorrentes podem ter objetivos dominantemente defensivos, como conseguir melhor posição negociadora frente a países mais poderosos, ou refletir os desejos de influência regional de algum país de maior peso específico na área. Em qualquer hipótese, é difícil escapar à percepção de que tal tendência à criação de blocos regionais poderá contribuir para o debilitamento do sistema multilateral de comércio ou, em todo caso, para consideráveis mudanças no jogo de forças que condiciona o seu funcionamento.

Paralelamente à expansão do regionalismo econômico, houve uma considerável ampliação da agenda multilateral do comércio mundial, fundamentalmente para atender aos interesses dos países desenvolvidos, especialmente os Estados Unidos. Para eles, era preciso ampliar a competência do Gatt, de modo que a organização que se ocupava do comércio mundial de bens passasse a tratar também de outros temas que, num mundo globalizado, tinham-se tornado importantes para as economias mais avançadas. Assim, quando, em 1986, foi lançada, 
formalmente, a Rodada Uruguai, no Gatt, a inclusão de três "novos temas" na agenda de negociações - "direitos de propriedade intelectual relacionados com o comércio" (mais freqüentemente conhecidos pela sigla inglesa Trips), "medidas de investimento relacionadas com o comércio" (ou Trims) e o comércio internacional de serviços - era ponto fundamental para os países desenvolvidos.

Para os países em desenvolvimento, a situação apresentava-se de forma diferente. Muitos deles, inclusive o Brasil, haviam-se convertido ou estavam-se convertendo ao credo econômico liberal por tanto tempo pregado pelos países industrializados. Dentro de tal enfoque, já não se tratava, pois, de batalhar pela mudança dos princípios mesmos que formalmente norteavam o sistema vigente, mas, sobretudo, de conseguir que o discurso teórico valesse também na prática - e para todos. Afinal, se o liberalismo era desejável, por que deveriam os agricultores dos países ricos ser sustentados por subsídios internos e à exportação e protegidos por barreiras alfandegárias, enquanto os exportadores os das nações mais pobres eram penalizados por esses e outros mecanismos protecionistas? Mais genericamente, como considerar satisfatório o funcionamento de um sistema internacional de comércio que, como já assinalado, levava - mesmo quando formalmente respeitado - a uma liberalização muito maior do intercâmbio de bens entre países industrializados do que das compras provenientes das economias em desenvolvimento? Do ponto de vista dos países pobres, antes de falar em "novos temas", de interesse das economias mais avançadas, cabia, pois, eliminar tais anomalias, de modo a estabelecer o level playing field tão presente no discurso político, mas tão ausente na prática comercial dos países ricos. Em certo sentido, houvera, assim, uma inversão de posições, com os países pobres defendendo velhas noções de livre acesso aos mercados, especialmente os dos países ricos, enquanto estes se entregavam ao chamado "novo protecionismo", essencialmente seletivo.

O século atual iniciou-se, pois, com uma ordem econômica internacional significativamente distinta daquela que se tratara de estabelecer ao término da Segunda Guerra Mundial. Essa nova situação coloca o Brasil - e mais genericamente, os países em desenvolvimento de renda média - frente a desafios distintos daqueles com que se defrontara durante quase toda a segunda metade do século passado. 


\section{Nova distribuição de forças, novos desafios}

Tornou-se corriqueiro assinalar que o período entre os fins das décadas de 1940 e de 1980 foi marcado pelo bipolarismo político e pela trilateralização do poder econômico. De acordo com tal percepção, a ordem política internacional teria refletido, durante aquelas quatro décadas, o acordado em Yalta, onde se dividira o mundo em uma grande área de influência americana e outra soviética, com a linha divisória entre ambas, definida pela posição ocupada na época pelas forças ocidentais e pelas de Moscou. Tal situação impediu que a efetiva redistribuição do poder econômico entre os Estados Unidos, a Europa Ocidental e o Japão, ocorrida a partir da reconstrução das economias destruídas pela guerra, se refletisse numa redistribuição correspondente do poder político-militar. Manteve-se destarte a coesão do mundo ocidental, ou seja, da área sob a hegemonia americana, apesar de, no plano estritamente econômico, esta ter-se tornado discutível.

Menos enfatizado é o fato de que, paralelamente a essa difusão do poder econômico entre os países desenvolvidos do Ocidente, houve também um aumento do peso econômico relativo de um certo número de países em desenvolvimento de renda média. Assim, no fim do século passado, seis das 15 maiores economias do mundo - China, Índia, Brasil, México, Indonésia e Coréia do Sul - eram países em desenvolvimento. ${ }^{7}$ Confirmando - e de forma talvez mais marcante - essa tendência à redistribuição internacional do poder econômico, um estudo recente do banco suíço UBS conclui que, com base na paridade do poder aquisitivo das moedas, "o poder de compra dos consumidores chineses e indianos será cinco vezes mais importante do que o poder de compra atual dos EUA". ${ }^{8}$ Os autores do estudo consideram que suas projeçôes se basearam em hipóteses de crescimento "prudentes". Nada disso significa que as assimetrias de renda e de poder econômico internacional entre países pobres e ricos tendam, no conjunto, a diminuir num futuro previsível. A esmagadora maioria dos países em desenvolvimento continua

\footnotetext{
7 As comparações entre diferentes economias aqui citadas baseiam-se na paridade do poder aquisitivo das moedas e em dados do Banco Mundial. Foram publicadas em The Economist, 8 de maio de 1999, $110 \mathrm{p}$.

${ }^{8}$ Valor, 24.8.2004, p. A9.
} 
imensamente pobre e achacada pelas mazelas do subdesenvolvimento. Mesmo aqueles que aumentaram significativamente o próprio espaço na economia internacional, como os acima citados, continuam individualmente débeis frente a seus parceiros desenvolvidos.

Paralelamente a essa dupla redistribuição do poder econômico, o brusco desaparecimento do bipolarismo político veio transformar o quadro que, durante quatro décadas, condicionara a atuação internacional dos países em desenvolvimento, inclusive na área econômica.

O grande desafio com que se defronta aquele grupo de países pobres que ascendera na escala internacional do poder econômico é, pois, o de, nas novas circunstâncias, traduzir em maior poder de negociação os importantes progressos realizados. Trata-se de um problema agudamente sentido pelo Brasil, cuja situação política e econômica, tanto nacional como internacional, mudou consideravelmente desde a metade do século passado.

\section{Brasil: nova realidade, novos desafios}

Em 1950, a economia brasileira tinha dimensões relativamente modestas no âmbito mundial. $\mathrm{O}$ total do nosso comércio exterior (exportações mais importações) era da ordem de 2,3 bilhões de dólares, e nele, o café respondia por mais de $50 \%$ do valor das exportaçóes. Ao encerrar-se o século, o Brasil, com base na mesma escala comparativa usada acima, era a nona economia do mundo, e nosso intercâmbio com o exterior já se elevava a cerca de 100 bilhões de dólares, com uma significativa participação de produtos manufaturados e semimanufaturados em nossa pauta de exportações. Este ano espera-se que nossas vendas ao estrangeiro excedam os 80 bilhōes - e as disputas comerciais com outros países envolvem questôes ligadas à exportação de bens como avióes a jato e produtos siderúrgicos. Tanto as dimensões da economia brasileira, como a inserção internacional do Brasil passaram, pois, na segunda metade do século XX, por enormes mudanças quantitativas e qualitativas.

Por outro lado, ocorreram, sobretudo a partir de 1990, significativas alterações na nossa política econômica, bem como mudanças de ênfase e de percepção em nossa política externa. Até 1980, a economia brasileira crescera a uma das taxas mais altas do mundo e nossa política 
econômica era claramente protecionista. Vivíamos o período da chamada "substituição de importaçôes". Paralelamente, nossa política externa, no mesmo período, era marcada, com variações de ênfase relativa por duas constantes - o desenvolvimento econômico e, no contexto da Guerra Fria, a fidelidade de última instância ao bloco ocidental. Em 1990, já terminada a Guerra Fria e esgotado o modelo de substituição de importações, houve uma mudança de percepções.

A questão do desenvolvimento passou a ser vista dentro de um enfoque econômico liberal, o que, sem varrê-lo das preocupações da nossa diplomacia, reduziu consideravelmente seu papel de elemento condicionante da nossa política externa. Como bem sintetizou Amado Cervo, "o desenvolvimento não desapareceu no horizonte da política exterior brasileira desde 1990. [...] Deixou apenas de ser o elemento da sua racionalidade". 9 Paralelamente, a fidelidade de última instância ao bloco ocidental e à liderança americana - que objetivamente perdera sua razão de ser com o fim da Guerra Fria - foi, em alguma medida, substituído pela absorção acrítica do pensamento econômico emanado de Washington.

Ao assumir o poder comprometido com o progresso econômico e social do país e ao declarar que uma das condições para a construção de um "novo modelo econômico seria garantir a presença soberana do Brasil no mundo", o atual governo assumiu, até certo ponto, ênfases e conflitos tradicionais da nossa diplomacia. Não foi à toa que as relações com Washington, sobretudo na área econômica, passaram a ser uma das grandes indagações dos meios de comunicação sobre a política externa do governo Lula. Tratava-se, entretanto, de um contexto nacional e internacional substancialmente distinto do prevalecente antes da década de 1990. O problema passou a ser, pois, como atender a preocupaçôes antigas com objetivos específicos e instrumentos de ação diplomática distintos.

Assim, o discurso de defesa dos interesses dos países em desenvolvimento não perdeu, como tal, sua validade básica, mas suas implicaçōes operacionais de política externa são diferentes daquelas pelas quais optamos no passado. Hoje, não se trata tanto, pelo menos

${ }^{9}$ CERVO, Amado Luiz. Relações Internacionais do Brasil: um balanço da era Cardoso, Revista Brasileira de Política Internacional, ano 45, n 1, p. 7. Brasília: Instituto Brasileiro de Relações Internacionais, 2002. 
do ponto de vista brasileiro, de modificar os fundamentos do sistema internacional de comércio, por exemplo, mas antes de avançar em áreas mais limitadas, por meio de fórmulas operativas que dificilmente terão o apoio de todo o universo dos países em desenvolvimento. Em outras palavras, o importante hoje é obter benefícios sustentáveis, não a mera aceitação de princípios gerais, que facilmente poderiam ser desrespeitados em sua aplicação prática. Torna-se, portanto, mais relevante atuar em conjunto com uns quantos países selecionados, que efetivamente aumentem nosso poder de negociação, do que ter o apoio nominal de um vasto número de atores teoricamente afins, mas que, numa negociação concreta, trarão mais dificuldades do que ajuda. A diferença entre o relativo principismo inevitável de antes e o pragmatismo necessário de hoje é ilustrada por dois episódios concretos. A idéia de um sistema geral de preferências dos países desenvolvidos em favor dos países em desenvolvimento foi aprovada inicialmente na II Unctad, em 1968, graças à pressão do Grupo dos 77 - que na verdade, já reunia um número muito maior de países em desenvolvimento. A aprovação da resolução respectiva só foi conseguida, porém, graças ao recurso à votação nominal de vários parágrafos, de modo a inibir a defecção de muitos países em desenvolvimento, que nela viam poucos ganhos potenciais próprios ou que já gozavam das vantagens de esquemas preferenciais seletivos, que seriam erodidas pela generalização do benefício. A aplicação prática da idéia, entretanto, só poderia dar-se, entretanto, mediante um waiver, a ser obtido individualmente no Gatt pelos países que se dispusessem a outorgar tais preferências. A impossibilidade de o conjunto dos países em desenvolvimento exercerem uma pressão adequada no âmbito do Acordo Geral e o próprio processo decisório, neste foro, permitiram que, na prática, a proposta global inicialmente aprovada fosse convertida em uma série de esquemas nacionais, que cada país outorgante tratou de fazer o menos oneroso possível. Essa diluição do poder de pressão de um grupo numeroso, mas heterogêneo, contrasta com o exemplo recente da atuação do G-20, no âmbito das negociações da Rodada de Doha, na Organização Mundial de Comércio, quando este grupo relativamente pequeno se revelou uma força negociadora com peso suficiente para que suas posiçóes tivessem de ser levadas em conta pelas potências econômicas tradicionais. Tratava-se, porém, de uma coalizão de países em 
desenvolvimento que reunia algumas das grandes economias do planeta e Estados de considerável projeção regional (China, Índia, Brasil, África do Sul são bons exemplos) e que soube superar ou contornar divergências tópicas intragrupo para atuar com coesão operacional, profissionalismo e eficiência.

As implicações dessa mudança de estratégia, decorrente da redistribuição internacional do poder econômico e de mudanças de enfoque em nossa política econômica, não se limitam, porém, a nossa atuação em organismos multilaterais. Elas se fazem sentir também nas relações regionais e bilaterais do Brasil, particularmente num momento em que o regionalismo econômico tende a ganhar força frente ao multilateralismo. Isso fica bem claro no âmbito continental.

A conversão dos Estados Unidos ao regionalismo e o conseqüente lançamento das negociações da Alca colocaram o Brasil diante de opções extremamente difíceis. Aceitar a iniciativa americana na forma proposta por Washington hipotecaria nosso desenvolvimento e autonomia futuros. Alternativamente, ficar de fora do processo negociador, provavelmente, nos deixaria isolados e em desvantagem competitiva em nossa própria região, já que nossos vizinhos - coletivamente ou em arranjos bilaterais com Washington - tendem a estabelecer laços preferenciais com os EUA. A alternativa percebida como mais razoável foi tentar negociar uma Alca mais favorável aos interesses brasileiros e, mais genericamente, aos latino-americanos. Isso é, porém, praticamente inviável sem o apoio de, pelo menos, um número significativo de outros países sul-americanos. Mas aqui nos chocamos com sérias dificuldades.

Uma tentativa de reviver, frente às duas grandes economias desenvolvidas do norte do continente, um latino-americanismo baseado no subdesenvolvimento comum dos países ao sul do rio Grande já não teria sentido prático, se é que chegou a tê-lo no passado. Ainda no governo anterior, a percepção de tais dificuldades ficou muito clara quando na convocação da Cúpula Sul-Americana de Brasília, em 2000. Na época, o então ministro das Relações Exteriores, embaixador Luís Felipe Lampreia, referindo-se à iniciativa brasileira, salientou "a especificidade da América do Sul, particularmente no âmbito econômico-comercial, pelo que teriam sido deixados de fora do projeto a América Central e o Caribe, vinculados de forma mais próxima e direta à América do Norte, em particular aos 
Estados Unidos'” ${ }^{10} \mathrm{~A}$ iniciativa não visava, pois, a reunir os países pobres do continente, mas, sim, aqueles pobres menos próxima e diretamente vinculados aos Estados Unidos. Embora não declaradamente, dava-se um passo no sentido do sul-americanismo, um regionalismo continental mais pragmático, que - embora sem rejeitá-los abertamente - afastavase tanto do velho pan-americanismo de inspiração monroísta quanto da noção mais recente de um latino-americanismo desenvolvimentista, alicerçado na presumida afinidade do subdesenvolvimento. Ampliava-se, pois, a percepção política regional que inspirara a Alcsa, de modo a ensejar uma reflexão abrangente sobre "um projeto pragmático de organização do espaço sul-americano". ${ }^{11}$

O governo atual tem seguido a mesma trilha de congregação dos países da América do Sul, porém com menos ênfase em esquemas declaradamente abrangentes - como a Área de Livre Comércio SulAmericana ou a reunião de cúpula de Brasília - e maior disposição de assumir atitudes protagônicas no âmbito regional. Já não se trata agora de lançar grandes esquemas de âmbito subcontinental, que dificilmente chegam a dar frutos, mas de fazer avançar projetos regionais já existentes, de estimular a vinculação entre eles - como a ligação MercosulComunidade Andina - e de tomar iniciativas bilaterais ambiciosas, como no caso da Venezuela, assumindo, ainda que apenas implicitamente, uma atitude de liderança dentro da América do Sul.

Tudo isso revela maior desenvoltura em nossa atual política regional, e uma mudança em relação à atitude anterior, que se preocupava em negar qualquer noção de que o Brasil pretendesse tomar uma posição de líder sub-regional. Ela não elimina, entretanto, as dificuldades decorrentes das peculiaridades da posição do Brasil no continente.

Com uma população da ordem de 180 milhóes de habitantes, a maior e mais desenvolvida economia da América do Sul, sem disputas territoriais pendentes com qualquer dos seus vizinhos, nosso país constitui, inevitavelmente, um pólo de atração econômica e política no subcontinente. Em tese teria, pois, condições para exercer um papel

10 SOUTO MAIOR, Luiz A. P. O Brasil em um mundo em transição. Brasília: Editora UnB/IBRI, 2003, 148p.

${ }^{11}$ LAMPREIA, Luís Felipe. Cúpula da América do Sul. Carta Internacional. no 87, ano VIII. São Paulo: USP, maio de 2000. 
de liderança tranqüila na região. Todos esses fatores tendem a ser, porém, parcialmente ofuscados por considerações objetivamente menos evidentes, mas nem por isso menos relevantes. Séculos de relações centroperiferia condicionaram as naçôes sul-americanas - e a própria opinião brasileira não é alheia a tal condicionamento - a buscarem na América do Norte e na Europa (mais recentemente também na Ásia) os mercados desejáveis e a liderança internacional aceitável. Nesse contexto, é ilustrativo que os países da região tendam a perceber as ligaçōes viárias transcontinentais mais como "uma saída para o Atlântico" (ou para o Pacífico, em sentido inverso), do que vínculos econômicos intra-regionais. Esta é a maneira como, nos países andinos, freqüentemente se vê o tão desejado acesso ao rio Amazonas ou como boa parte da opinião brasileira percebe estradas para o Chile ou o Peru, por exemplo. Só lentamente a popularização da idéia de integração econômica regional foi levando os governos a se preocuparem mais efetivamente com a indispensável "integração física” da área. Paralelamente, as próprias assimetrias de dimensões e de peso econômico tendem a exacerbar rivalidades e temores históricos, complicando não só o exercício de uma possível liderança brasileira, mas a própria integração sub-regional.

O Mercosul ilustra bem tal situação. Firmado em março de 1991, o Tratado de Assunção comprometia seus quatro signatários com a constituição de um mercado comum, que deveria "estar estabelecido a 31 de dezembro de 1994" e que implicaria, entre outras coisas, "a livre circulação de bens, serviços e fatores produtivos entre os países”. ${ }^{12}$ Assim definido, tratava-se de um objetivo pouco realista, dadas a complexidade da tarefa e a exigüidade do prazo. Mais importante para o objeto da presente reflexão, implicava também uma visão estratégica comum da posição dos quatro em suas relaçóes recíprocas. Igualmente no tocante a países de fora da área, já que também se comprometiam, no mesmo artigo, a estabelecer uma tarifa externa comum e à "adoção de uma política comercial comum em relação a terceiros Estados ou agrupamentos de Estados". Na realidade, apesar de afirmativas em contrário, tal visão estratégica comum parece inexistir. Isso ficou flagrante entre o Brasil e a Argentina durante a década de 1990, no governo Menem, adepto do

12 Tratado de Assunção, artigo 1. 
chamado "realismo periférico" e interessado em fazer de suas "relações carnais" com os EUA um instrumento de preeminência política no Cone Sul. Tal quadro modificou-se com a assunção dos governos Lula e Kirchner. Do lado brasileiro, há uma nova disposição de promover o aperfeiçoamento institucional do Mercosul, chegando-se mesmo a mencionar o objetivo de uma política externa comum. Do lado argentino, também parece haver a disposição de um melhor entendimento frente a terceiros, mas, por outro lado, há claras indicações de preocupação com uma possível preeminência do Brasil no âmbito do próprio processo de integração do Cone Sul. Isso se traduz em medidas protecionistas como as da chamada "guerra das geladeiras" e, de modo geral, na declarada disposição de travar o livre comércio com o Brasil e mesmo certas migrações de investimentos entre países-memb até que seja possível "reindustrializar a Argentina”. Se juntarmos isso à aparente reticência em relação a uma possível escolha do Brasil como membro permanente do Conselho de Segurança da ONU, teremos um quadro bem mais amplo e profundo de rivalidade geopolítica, e não apenas econômica, pouco compatível com o ambicioso projeto de integração proclamado. Em todo caso, uma visão peculiar do que tal integração deve significar. A experiência de mais de treze anos de Mercosul autoriza certo ceticismo quanto à probabilidade de que tais diferenças de percepção e de objetivos venham a ser superadas.

Em síntese, o grande desafio para a nossa política externa no continente - com implicações mais amplas para nossa política internacional - decorre de estarmos colocados entre duas percepções regionais de poder que afetam conflitantemente nossos interesses. De um lado, um projeto patrocinado pelos Estados Unidos, que - por meio da Alca ou de uma rede de acordos preferenciais bilaterais com países latino-americanos - criaria uma vinculação econômica assimétrica desses últimos em relação a Washington, com inescapáveis implicações políticas. De outro, um esquema de integração sub-regional sul-americano, que em tese poderia reforçar consideravelmente a posição negociadora das nações da área frente aos EUA, mas que se vê ameaçado por velhas rivalidades no seu próprio âmbito. Nele teríamos uma preeminência natural, mas nosso principal aliado potencial prefere pôr em risco todo o projeto a permitir que, nele ou por meio dele, o Brasil venha a ter uma posição 
no continente e uma projeção no mundo consentâneas com seu peso econômico e demográfico.

Até agora, temos feito sucessivas concessões, na aparente convicção de que assim conseguiremos manter vivo o Mercosul. Isto seria visto como um objetivo desejável em si mesmo - e de fato o é. Seria também importante para uma negociação frutífera com os Estados Unidos, com vistas a fazer da Alca um projeto palatável. Frente à atitude dúbia de nosso principal parceiro, cabe perguntar, entretanto, se o Mercosul que poderíamos salvar mereceria realmente ser salvo. Na hipótese negativa, deveríamos considerar seriamente alternativas a um projeto de integração desejável em tese, mas que crescentemente se revela utópico. Em seu lugar, poderíamos pensar, por exemplo, na negociação de acordos preferenciais bilaterais com países ou grupos de países vizinhos efetivamente dispostos a cooperar conosco. Tratar-se-ia, em última análise, de usar seletivamente o trunfo que representa o acesso preferencial ao nosso mercado, de modo a criar uma rede de acordos que nos livrasse do isolamento decorrente de um provável êxito do projeto de Washington e fortalecesse nossa posição no subcontinente. Deixaríamos, assim, de insistir num projeto de integração sub-regional que poderia ser vantajoso para os quatro países que hoje o integram, desde que todos estivessem convencidos de que não se trata de um jogo de soma zero, onde o ganho de um sempre representa prejuízo para algum dos outros. Tal convicção parece, entretanto, inexistir em Buenos Aires. Melhor será, portanto, que continuemos a tratar a Argentina com a importância que ela sempre terá no contexto geral de nossa política regional, mas sem muito otimismo quanto à sua disposição de arcar com as responsabilidades inerentes à participação construtiva em um projeto de integração.

Em parte, o raciocínio subjacente ao que foi dito em relação a nossa atuação no âmbito continental aplica-se também a nossa política internacional. $\mathrm{O}$ multilateralismo econômico limita-se hoje a reger as relações entre países que não integram um mesmo arranjo regional ou aqueles aspectos das relações econômicas intra-regionais não adequadamente regulados pelos instrumentos respectivos. Não tem, pois, a universalidade que um dia pretendeu alcançar. Por outro lado, os esquemas regionais, surgidos nas últimas três décadas, são freqüentemente marcados pela participação de países desenvolvidos, que 
assim tendem a tornar-se os pólos de zonas econômicas de influência. Esse é o caso, por exemplo, da União Européia em relação aos países associados da África, do Caribe e do Pacífico (ACP), como será o dos Estados Unidos em relação à América Latina, caso a Alca venha a ser estabelecida na forma proposta por Washington. Isso coloca diante de sérios desafios um país como o Brasil, que não deseja ser apenas parte de uma zona de influência econômica, mas que já não encontra no multilateralismo de âmbito mundial uma adequada alternativa ao regionalismo.

Freqüentemente, descrevemos o Brasil como um global trader, em razão da diversificação geográfica das nossas exportações. Dada a modesta participação do país no conjunto do comércio mundial, tal caracterização pode parecer algo pretensioso, mas ressalta a determinação brasileira de manter vínculos comerciais com o maior número possível de países, evitando assim uma dependência exagerada em relação a qualquer mercado individual. Isso nos obriga, por um lado, a participar ativamente dos organismos econômicos multilaterais, especialmente a Organização Mundial de Comércio (OMC). Para ser efetiva, tal participação exige, porém, um constante esforço de coordenação com países afins, de modo a aumentarmos nossa capacidade de influir efetivamente nas decisóes tomadas naqueles foros, a exemplo da já citada iniciativa que levou à formação do G-20. Por outro, em um mundo onde proliferam os arranjos preferenciais, temos de ampliar o leque de países com os quais devemos manter relações particularmente estreitas. Isso inclui negociar acordos bilaterais ou plurilaterais que não apenas nos assegurem condições competitivas de acesso a determinados mercados, mas também favoreçam outras formas de cooperação com países selecionados. É o que temos procurado fazer no tocante à China e à Índia, por exemplo.

\section{Conclusões}

O sistema econômico multilateral foi sendo erodido de várias maneiras ao longo da segunda metade do século XX. Em particular, a partir da década de 1980, multiplicaram-se os acordos econômicos regionais, com forte participação de países desenvolvidos, para o que muito contribuíu a conversão dos Estados Unidos ao credo regionalista 
que até então rejeitava. Tal evolução teve sérias implicações para o Brasil, sobretudo desde que Washington propôs o estabelecimento de uma área hemisférica de livre comércio.

Nosso país tem hoje um peso econômico internacional e, sobretudo, regional que lhe dá a possibilidade - e em certo sentido lhe cria o dever - de ser mais do que outro participante incaracterístico da área de influência de uma grande potência ou do mundo em desenvolvimento em seu conjunto. Alcançar tal desiderato esbarra, porém, em obstáculos vários.

Regionalmente, falta-nos poder de negociação suficiente para estabelecer um bloco coeso sul-americano, ou sequer do Cone Sul, que pudesse contribuir para dar ao projeto original de Washington formato mais palatável. O poder de atração da Alca sobre outros países sul-americanos e rivalidades político-econômicas regionais dificultam a concretização de tal desígnio. Falta-nos, também, a força necessária para, sozinhos, opor-nos eficazmente ao projeto liderado por uma potência como os EUA ou formarmos, em termos adequados, uma aliança competitiva com outra, como a União Européia.

Tampouco faria sentido, nas atuais circunstâncias do Brasil e do mundo, tentar reviver e dar conteúdo operacional à suposta solidariedade entre países em desenvolvimento. A união dos países pobres foi uma idéia válida quando se tratava de obter a aceitação de princípios gerais favoráveis àqueles países e quando a rivalidade política da Guerra Fria levava os grandes a cortejarem o então chamado Terceiro Mundo. Já não o é, porém, quando se trata, como agora, de alcançar objetivos mais limitados e concretos, que nos tragam vantagens palpáveis e sustentáveis.

Tudo isso deve levar-nos, pois, a uma atitude mais seletiva e pragmática de busca, tanto no âmbito mundial como no regional, de aliados selecionados em função de sua confiabilidade e capacidade de contribuir efetivamente para a consecução de objetivos concretos comuns. Será uma pena se esse pragmatismo nos forçar a sacrificar algumas "vacas sagradas “- ou mesmo, objetivos que em tese são desejáveis.

Setembro de 2004 


\section{Resumo}

Partindo da Segunda Guerra Mundial, o autor traça uma análise sobre o desenvolvimento da economia mundial, que de uma estrutura marcada pelo liberalismo e pelo multilateralismo, passa ao crescente regionalismo/ bilateralismo. Busca-se, assim, entender o porquê de tal transformação, examinando as diferenças entre o imediato pós guerra e a posterior conjuntura conseqüente das medidas adotadas em anterior época. $O$ artigo traz também uma reflexão sobre posicionamento atual do Brasil, em especial, com relação aos acordos bilaterais.

\section{Abstract}

The author surveys the development of the world economy since World War II, which has moved from a structure characterized by liberalism and multilateralism to increasing regionalism and bilateralism. The article attempts to understand the reason for this change by examining the differences between the postwar period and the subsequent situation that resulted from measures adopted earlier. Also included is a reflection on Brazil's stand, particularly with respect to bilateral agreements.

Palavras-chaves: Economia Internacional; Multilateralismo; Regionalismo; Brasil; Alca

Key words: International economy; Multilateralism; Regionism; Brazil; Alca 